\title{
Healing of fatigue crack in epoxy materials with epoxy/mercaptan system via manual infiltration
}

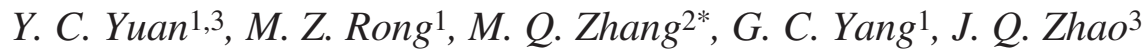 \\ ${ }^{1}$ Key Laboratory for Polymeric Composite and Functional Materials of Ministry of Education, DSAPM Lab, School of \\ Chemistry and Chemical Engineering, Sun Yat-sen University, Guangzhou 510275, P. R. China \\ ${ }^{2}$ Materials Science Institute, Zhongshan University, Guangzhou 510275, P. R. China \\ ${ }^{3}$ College of Materials Science and Engineering, South China University of Technology, Guangzhou 510640, P. R. China
}

Received 12 May 2010; accepted in revised form 21 June 2010

\begin{abstract}
The present work verified the capability of epoxy/mercaptan/tertiary amine system for retarding and/or arresting fatigue cracks in epoxy materials subjected to cyclic loading at room temperature. By using static and dynamic manual infiltration methods, the effects of hydrodynamic pressure crack tip shielding, polymeric wedge and adhesive bonding of the healing agent were revealed. Depending on the applied stress intensity range and the competition between polymerization kinetics of the healing agent and crack growth rate, the above mechanisms exerted different influences on crack retardation under different circumstances. On the whole, the epoxy/mercaptan/tertiary amine system proved to be very effective in obstructing fatigue crack propagation. It formed a promising base for developing self-healing epoxy materials that enable in-situ autonomic rehabilitation of fatigue crack.
\end{abstract}

Keywords: smart polymers, fracture and fatigue, self-healing, epoxy

\section{Introduction}

Fatigue and fatigue failure are critical for polymeric materials used in structural applications. Under fatigue loading, cracks might slowly grow above a threshold range of stress intensity, $\Delta K_{t h}$, which is significantly lower than the critical stress intensity, $K_{I C}$. Therefore, imparting self-healing capability to polymers and polymer composites is an effective way to solve the problem [1-8]. It is hoped that the cracks can be autonomously eliminated soon after their emergence.

Earlier studies on metals have shown that infiltrating proper substances into a fatigue crack could induce crack growth retardation and even crack arrest [9-16]. Recently, Brown et al. [4] established a protocol to extend fatigue life of epoxy using dicyclopentadiene (DCPD). Viscous flow of DCPD in the crack plane retarded crack growth, and its polymerized version further acted as a wedge at the crack tip for artificial crack closure. On the basis of this pilot research, they prepared self-healing epoxy with embedded DCPD-loaded microcapsules and particulate Grubbs' catalyst, which was capable of responding to propagating fatigue cracks by autonomic processes that led to higher endurance limit and life extension, or even complete arrest of cracking [5-8], in addition to the ability to repair the cracks generated by monotonic fracture [17].

In fact, epoxy resin has been employed as infiltrant material for obstructing fatigue crack development in metals [9-13]. It has the advantages like good adhesiveness, low cure shrinkage, broad compatibility, corrosion and chemical resistance, strength and durability. In particular, the epoxy/mercaptan/ tertiary amine system (the basis of '5-min epoxies') is highly reactive. It can come to a practical han- 
dling strength in minutes at room temperature and develop useful bond strengths at ambient temperatures as low as $-20^{\circ} \mathrm{C}$. Therefore, it should be favorable for repairing fatigue damages under cyclic loading.

In our previous work, self-healing epoxy composites containing dual encapsulated healant, i.e. two types of microcapsules that respectively include epoxy prepolymer as the polymerizable component and mercaptan/tertiary amine catalyst as the hardener, were made [18-21]. Upon fracture the unreacted epoxy can be bled into damage sites together with the hardener fluid and then polymerized to repair cracks. The system proved to work in the case of monotonic fracture as characterized by the attractive healing effect even below room temperature. As a continuation of our project, the present work is focused on examination of the performance of the epoxy/mercaptan/tertiary amine system in suppression and rehabilitation of fatigue crack in epoxy materials via manual infiltration. Effect of adhesive curing process on fatigue crack propagation was systematically studied. The results are expected to provide a knowledge frame for the subsequent in-situ self-healing that has the practical value for engineering application.

\section{Experimental}

\subsection{Materials and specimen preparation}

Tapered double cantilever beam (TDCB) specimens were cast from the mixture of epoxy resin (EPON 828, diglycidyl ether of bisphenol A, Hexion Specialty Chemicals, USA) and 12.5 pph curing agent (diethylenetriamine, DETA, Shanghai Medical Group Reagent Co., China). The mixture was degassed, poured into a closed silicone rubber mold and cured for $24 \mathrm{~h}$ at room temperature, followed by $48 \mathrm{~h}$ at $40^{\circ} \mathrm{C}$. Table 1 shows the material properties.

Table 1. Properties of the cured epoxy (EPON 828/DETA)

\begin{tabular}{|l|c|}
\hline \multicolumn{1}{|c|}{ Properties } & Data \\
\hline Density $\left[\mathrm{kg} / \mathrm{m}^{3}\right]$ & 1172 \\
\hline$K_{I C}\left[\mathrm{MPa} \cdot \mathrm{m}^{1 / 2}\right]$ & $0.587 \pm 0.016$ \\
\hline Tensile strength $[\mathrm{MPa}]$ & $42.3 \pm 0.4$ \\
\hline Young's modulus $[\mathrm{GPa}]$ & $3.7 \pm 0.2$ \\
\hline "Paris power law exponent, $n$ & 7.12 \\
\hline "Paris power law constant, $C_{o}$ & 0.11 \\
\hline
\end{tabular}

*Note: $n$ and $C_{o}$ were obtained according to Equation (3). The data well agree with those reported in ref. [23].
The healing agent consists of epoxy (1:1 mixture by weight of EPON 828 and diglycidyl ether of resorcin (J-80, Wuxi Resin Factory of Bluestar New Chemical Materials Co., China)) and the hardener (pentaerythritol tetrakis (3-mercaptopropionate) (PMP, Fluka Chemie AG, Switzerland) and 2,4,6-tris(dimethylaminomethyl)phenol (DMP-30, Shanghai Medical Group Reagent Co., China). Weight ratio of epoxy/mercaptan/tertiary amine $=$ $6 / 5 / 1$.

\subsection{Mechanical testing and characterization}

Fatigue crack propagation behavior of epoxy specimens was investigated using the aforesaid TDCB specimen geometry (with groove length of $55 \mathrm{~mm}$ ) $[4,21,22]$ on a Shimadzu Air Servo Fatigue and Endurance Testing System ADT-AV02K1S5 with $2 \mathrm{kN}$ load cell at room temperature $\left(24 \pm 1^{\circ} \mathrm{C}\right)$. Specimens were pre-cracked $(0.5-1.5 \mathrm{~mm})$ with a razor blade while ensuring the pre-crack tip was centered in the groove and then pin loaded. A triangular waveform of frequency $5 \mathrm{~Hz}$ was applied with a stress ratio $\left(R=K_{\min } / K_{\max }\right.$, where $K_{\min }$ and $K_{\max }$ denote the minimum and maximum values of the cyclic stress intensity, respectively) of 0.1 , unless otherwise specified for the examination of the impact of $R$. Fatigue cracks were grown within constant mode-I stress intensity factor range, $\Delta K_{I}$ $\left(\Delta K_{I}=K_{\max }-K_{\min }\right)$. Load line crack opening displacement (COD) was measured by a clip gauge. Crack lengths were measured optically and by specimen compliance [23].

Due to the complexity of healing a growing crack under fatigue circumstances, retardation and arrest of fatigue cracks were found to be dependent on the range of applied cyclic stress intensity, $\Delta K_{I}$, as well as the competition between polymerization kinetics of the healing agent and crack growth rate [5-8]. Accordingly, static and dynamic infiltration experiments were designed and conducted as follows. For the static one, after a crack growth increment of $\sim 8 \mathrm{~mm}$, both the growth rate and crack closure response settled down to steady state values. At this point, about $0.5 \mu \mathrm{l}$ of pre-mixed healing agent was injected into the crack plane by using a microsyringe. The mixing of the components of the healing agent took about $30 \mathrm{sec}$ and the injection was completed within $10 \mathrm{sec}$. All the times were calculated from the start time of mixing of the healant (i.e. $0^{\prime}$, 
the single quotation mark represents minute hereinafter). The healing agent flowed backward and forward in the fracture plane and instantaneously evenly penetrated into the crack. After 10 seconds, the test was stopped and the crack held open at a constant load level. Fatigue loading was reestablished after a prescribed steady-state healing period. In the case of dynamic experiments, the testing procedures were the same as those applied for the static ones, except that fatigue loading wasn't interrupted after the manual infiltration.

The constant $\Delta K$ nature of the fatigue test yielded a constant crack growth rate over the majority of the length of the specimen [4]. Experimental errors mainly came from the initial stage of cracking because of a slight deflection of the pre-crack. In order to reduce data discreteness, the data within $2 \mathrm{~mm}$ of initial crack length $(a=19-21 \mathrm{~mm})$ were discarded for all the specimens except those the healing agent had repaired. For each test, the result was an average of four specimens.

The healing efficiency, $\lambda$, was defined by fatigue life extension [4], defined by Equation (1):

$\lambda=\frac{N_{\text {Control }}-N_{\text {Healed }}}{N_{\text {Control }}}$

where $N_{\text {Healed }}$ and $N_{\text {Control }}$ denote the total number of cycles to failure of a healed specimen and that of a similar specimen without healing, respectively.

To evaluate fracture toughness, $K_{I C}$, of the cured epoxy (i.e. EPON 828/DETA), a natural pre-crack $(\sim 2 \mathrm{~mm})$ was created on the TDCB specimen by inserting a fresh razor blade and gently tapping into the molded notch starter [21]. Subsequently, the specimen was pin loaded and tested with a Hounsfied H10 KS universal testing machine under displacement control using a $3 \mathrm{~mm} / \mathrm{min}$ displacement rate at room temperature. For determination of fracture toughness, $K_{I C}$, of the cured healing agent, the epoxy TDCB specimen made of EPON 828/DETA was fractured only to the end of the groove and then about $3 \mu \mathrm{l}$ of uniformly pre-mixed healing agent (i.e. EPON 828/J-80/PMP/DMP-30) was injected into the cracked face. Afterwards, the specimen was unloaded and left to cure for different times at room temperature. A natural pre-crack $(2-10 \mathrm{~mm})$ along the original crack route was rapidly created within one minute before the next test. Finally, the healed specimen was tested again following the above procedure.
Isothermal curing kinetics of the healing agent was studied with a TA differential scanning calorimeter (DSC) Q10 calorimeter in $\mathrm{N}_{2}$ at $25^{\circ} \mathrm{C}$. Morphological observation of the fracture surfaces was conducted on a Hitachi Model S-4800 field emission scanning electron microscope (SEM).

\section{Results and discussion}

\subsection{Hydrodynamic pressure crack-tip shielding}

Researches on fatigue crack propagation of metals immersed in fluid revealed that the forces required to squeeze the fluid out of the crack during unloading and to draw the fluid into the crack during loading provided effective crack-tip shielding [24-27]. Such a hydrodynamic pressure effect decreases the effective mode-I stress intensity factor range, $\Delta K_{\text {eff }}$, reduces fatigue crack growth rate and extends fatigue life. The Equation (2) can explain this mechanism:

$\Delta K_{\text {eff }}=\Delta K_{I}-\Delta K_{\text {opening }}-\Delta K_{\text {closure }}$

where $\Delta K_{\text {opening }}$ and $\Delta K_{\text {closure }}$ refer to the crackopening and crack-closure stress intensities from viscosity resistance of the liquid, respectively. In general, a fluid with higher viscosity leads to greater reduction in crack growth rate, until an upper limit is reached and the fluid can no longer penetrate to the crack tip [4, 24].

Like most polymers, the rate of steady-state fatigue crack growth of cured epoxy under constant applied range of stress intensity, $\Delta K_{I}$, can be described by the Paris power law [28], given by Equation (3):

$\frac{\mathrm{d} a}{\mathrm{~d} N}=C_{o} \Delta K_{I}^{n}$

where $C_{o}$ and $n$ are materials constants.

Figure 1 shows the dependence of fatigue crack length on loading cycle. On the basis of this dependence and the data in Table 1 as well, one can estimate the fatigue crack growth rate via Equation (3). Here in this work, the hydrodynamic pressure crack-tip shielding mechanism is investigated by infiltrating the polymerizable component of the healing agent (i.e. the 1:1 mixture by weight of EPON 828 and J-80, excluding the hardener) into the crack plane of the specimen without interrupting the fatigue experiment (i.e. dynamic infiltra- 


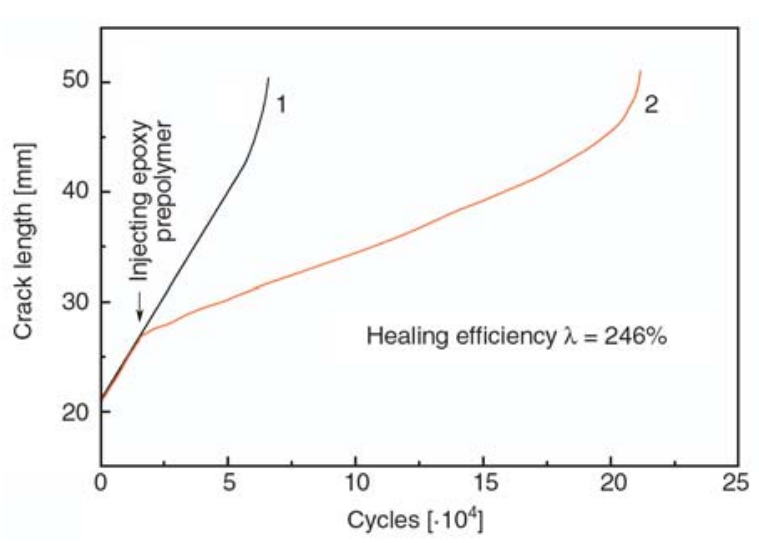

Figure 1. Crack length vs. fatigue cycles of (1) control fatigue specimen and (2) fatigue specimen with manual injection of epoxy prepolymer in dynamic infiltration fashion. Testing conditions: $K_{\max }=0.504 \mathrm{MPa} \cdot \mathrm{m}^{1 / 2}, K_{\min }=0.050 \mathrm{MPa} \cdot \mathrm{m}^{1 / 2}$, $\Delta K_{I}=0.454 \mathrm{MPa} \cdot \mathrm{m}^{1 / 2}, R=0.1$.

tion, see Experimental). For the control experiment, fatigue crack is grown in the specimen without injection until failure occurs (refer to curve 1 in Figure $1, N_{\text {Control }}=6.6 \cdot 10^{4}$ cycles). It is seen from Figure 1 that the slope of the crack length vs. fatigue cycles curve remains constant prior to the infiltration, suggesting a constant growth rate of approximately $3.8 \cdot 10^{-4} \mathrm{~mm} /$ cycle. After the infiltration, the crack growth rate is greatly reduced by $77 \%$ to $8.9 \cdot 10^{-5} \mathrm{~mm} /$ cycle. Like the case of submerged specimens [29], the subsequent crack propagation is also steady on the whole. According to Equation (1), the fatigue life-extension, $\lambda$, is calculated to be $246 \%$.

For metals, crack-tip shielding from hydrodynamic pressure provides about $50 \%$ reduction in crack growth rate. As for microcapsule-toughened epoxy specimen, infiltration of an inert mineral oil to the crack plane leads to $\lambda=101 \%$ [4]. Coupled with our data in Figure 1, it is understood that the hydrodynamic pressure mechanism resulting from viscous fluid operates more efficiently in polymeric materials. Further study in this aspect is needed to reveal the underlying factor.

In fact, the marked post-infiltration drop in the crack growth rate indicates that filling the crack with the epoxy prepolymer has a fair effect on the reduction in the crack-tip stress intensity, and thus lowers the crack growth rate. The maximum and minimum values of crack opening displacement (COD) and the corresponding load-displacement curves shown in Figures 2 and 3 further illustrate this variation trend. In contrast to the situation prior

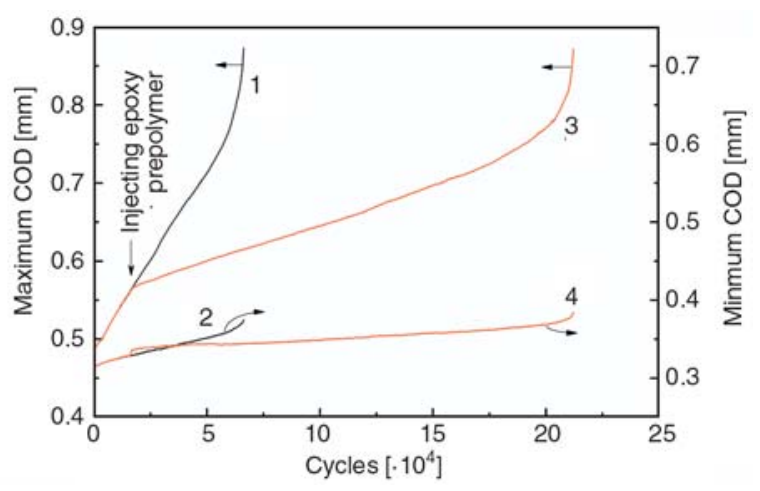

Figure 2. Maximum and minimum CODs vs. fatigue cycles of $(1,2)$ control fatigue specimens and $(3,4)$ fatigue specimens with manual injection of epoxy prepolymer in dynamic infiltration fashion. Testing conditions:

$K_{\max }=0.504 \mathrm{MPa} \cdot \mathrm{m}^{1 / 2}, K_{\min }=0.050 \mathrm{MPa} \cdot \mathrm{m}^{1 / 2}$, $\Delta K_{I}=0.454 \mathrm{MPa} \cdot \mathrm{m}^{1 / 2}, R=0.1$.

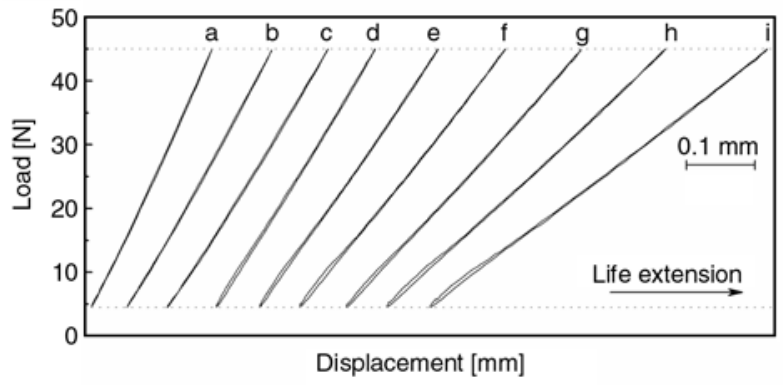

Figure 3. Load-displacement curves measured during selected cycles in Figure 2. Number of the fatigue cycles and the time after the manual infiltration of epoxy prepolymer: (a) 300 ;

(b) 9900 ; (c) $16200,0^{\prime}$; (d) $17100,3^{\prime}$; (e) $50100,113^{\prime}$; (f) $99900,279^{\prime}$; (g) 150000 , $446^{\prime}$; (h) 200 100, 613'; and (i) $211800,652^{\prime} .0^{\prime}$ means the time when the epoxy prepolymer is injected. Testing conditions:

$K_{\max }=0.504 \mathrm{MPa} \cdot \mathrm{m}^{1 / 2}, K_{\min }=0.050 \mathrm{MPa} \cdot \mathrm{m}^{1 / 2}$, $\Delta K_{I}=0.454 \mathrm{MPa} \cdot \mathrm{m}^{1 / 2}, R=0.1$

to the infiltration, the fatigue crack in the presence of the injected epoxy prepolymer cannot be fully opened at the maximum load, leading to a remarkably lower crack growth rate over a long period of time (curve 3 in Figure 2). In addition, the crack also cannot be fully closed at the minimum load and the COD values become nearly independent of fatigue cycles (curve 4 in Figure 2). As a result, hysteresis loops appear on the load-displacement relationship between the initial phase of crack opening and the end phase of crack closing (curves d-i in Figure 3). Obviously, the hysteresis resistance offered by the viscous epoxy prepolymer raises $\Delta K_{\text {opening }}$ and $\Delta K_{\text {closure }}$, and hence decreases $\Delta K_{\text {eff }}$ as indicated in Equation (2). 
With respect to the hardener component of the healing agent (i.e. the mixture of PMP and DMP-30), it exhibited approximately the same hydrodynamic pressure crack-tip shielding effect and fatigue lifeextension ability as epoxy prepolymer, probably because of their similar viscosities. Further research in this aspect is needed to reveal the reasons.

\subsection{Effects of cured wedge and its adhesiveness revealed by static infiltration tests}

Following the traditional crack closure concept, it is known that if the fatigue crack opening load is purposely increased by a wedge with adhesive properties at the crack tip, the effective stress intensity factor range would be reduced accordingly [9-13], as shown by Equation (4):

$$
\Delta K_{\text {eff }}=\Delta K_{I}-\Delta K_{\text {bonding }}-\Delta K_{\text {wedge }}
$$

where $\Delta K_{\text {bonding }}$ refers to the stress intensity due to the combined (tensile) stresses in adhesives across the crack faces, and $\Delta K_{\text {wedge }}$ refers to the crack-closure stress intensity due to the wedge from adhesives gelling and hardening. With this idea in mind, a number of investigations were carried out by artificially introducing crack surface contact [4, 9-16]. It can be concluded that size and performance of the wedge are the most crucial factors affecting the crack closure effect.

In this work, the pre-mixed epoxy based healing agent was injected into the crack plane forming a crosslinked epoxy wedge. The wedge size was adjusted by changing the load level required for holding the crack open after the infiltration, while the wedge performance was tuned by changing the steady-state healing time, during which cyclic loading paused and crack held open (see the Experimental for more details).

Figures 4 and 5 show the representative crack length versus fatigue cycles of the specimens healed at constant applied stress intensities, $K$, and the dependence of healing efficiency on $K$, respectively. Sharp et al. [11] indicated that the load level or stress intensity applied for holding the crack open played a decisive role in retarding or arresting fatigue crack. Evidently, it is true for the current system. Fatigue crack growth is retarded at different $K$ values (Figure 4). Higher stress intensity

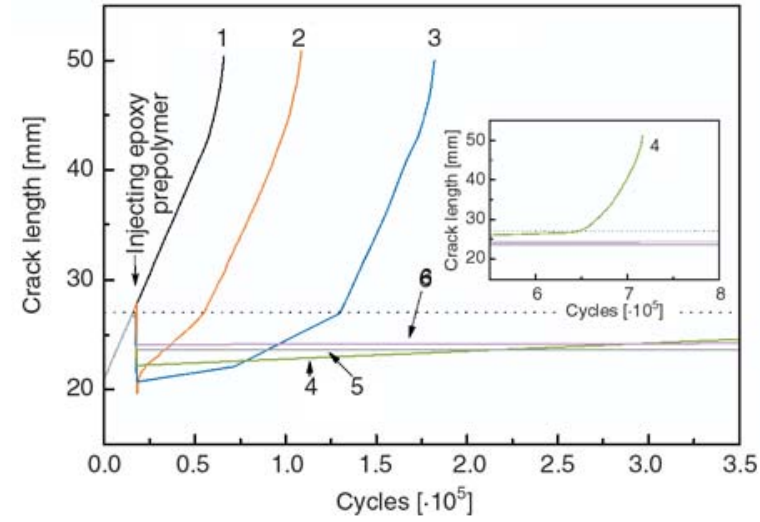

Figure 4. Crack length vs. fatigue cycles of (1) control fatigue specimen and (2-6) fatigue specimens with manual injection of pre-mixed healing agent in static infiltration fashion. The applied constant stress intensity for holding crack open after the injection: (2) 0 , (3) $0.112 \mathrm{MPa} \cdot \mathrm{m}^{1 / 2}$, (4) $0.224 \mathrm{MPa} \cdot \mathrm{m}^{1 / 2}$, (5) $0.336 \mathrm{MPa} \cdot \mathrm{m}^{1 / 2}$, and (6) $0.392 \mathrm{MPa} \cdot \mathrm{m}^{1 / 2}$. The steady-state healing time: $10 \mathrm{~min}$. Testing conditions: $K_{\max }=0.504 \mathrm{MPa} \cdot \mathrm{m}^{1 / 2}, K_{\min }=0.050 \mathrm{MPa} \cdot \mathrm{m}^{1 / 2}$, $\Delta K_{I}=0.454 \mathrm{MPa} \cdot \mathrm{m}^{1 / 2}, R=0.1$.

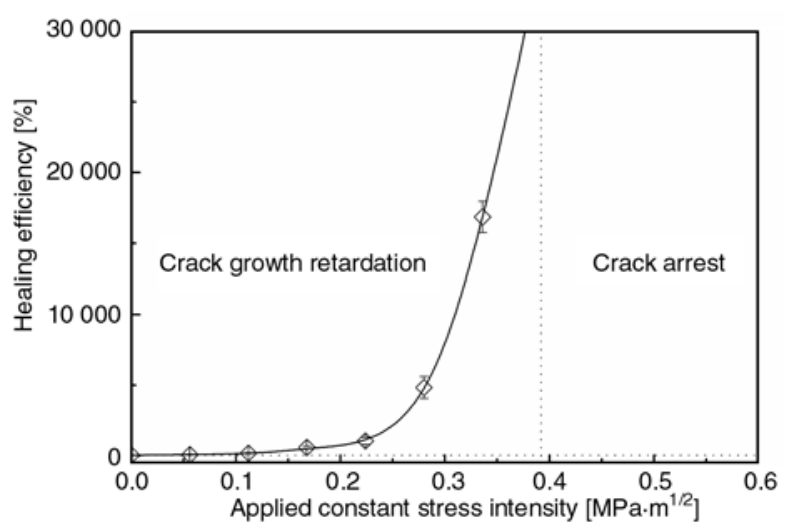

Figure 5. Healing efficiency of fatigue specimens with manual injection of pre-mixed healing agent in static infiltration fashion vs. the applied constant stress intensity for holding crack open after the injection. The data are calculated using the results in Figure 4.

applied during healing results in more prominent retardation effect (i.e. higher healing efficiency). When the applied stress intensity is not less than $0.392 \mathrm{MPa} \cdot \mathrm{m}^{1 / 2}$, crack can hardly advance for more than $10^{7}$ cycles and is considered to be completely arrested. Therefore, the applied stress intensity of $0.392 \mathrm{MPa} \cdot \mathrm{m}^{1 / 2}$ represents a watershed between fatigue crack growth retardation and crack arrest (Figure 5). The above results can be understood by the fact that thicker wedge is produced when the specimen is healed at higher applied stress intensity. Consequently, $\Delta K_{\text {wedge }}$ increases and $\Delta K_{\text {eff }}$ 
decreases (refer to Equation (4)). When $\Delta K_{\text {eff }} \leq$ $\Delta K_{\text {th }}$ (i.e. $\Delta K_{\text {bonding }}+\Delta K_{\text {wedge }} \geq \Delta K_{I}-\Delta K_{\text {th }}$ ), fatigue crack is fully arrested.

To look into the details of the retardation effect of the infiltrated epoxy based healing agent on fatigue crack growth, COD vs. fatigue cycles and load vs. displacement of the specimen healed at $0.112 \mathrm{MPa} \cdot \mathrm{m}^{1 / 2}$ are analyzed in the following as an example. It is seen that in the early stage when the healing agent has not been injected into the crack tip (refer to curve 3 in Fiure 4 and Figure 6), the corresponding load-displacement curves $\mathrm{a}$ and $\mathrm{b}$ in Figure 7 are linear with increasing compliance as the crack propagates. Following healing agent injection and cure, the load-displacement curve $\mathrm{c}$ in Figure 7 remains linear with reduced compliance due to the shorter (healed) crack length (refer to curve 3 in Figure 4). Accordingly, the crack cannot be fully opened at the maximum load as characterized by the deflected maximum COD vs. fatigue cycles (refer to curve 3 in Figure 6), and cannot be fully closed at the minimum load forming a terracelike minimum COD vs. fatigue cycles (refer to curve 4 in Figure 6). The results imply that the consolidated healing agent has formed a wedge that has certain affinity for the cracked faces. As a result, the crack opening and closing under cyclic loading is significantly obstructed.

When the cyclic stress intensity exceeds the applied constant stress intensity during healing, the infil-

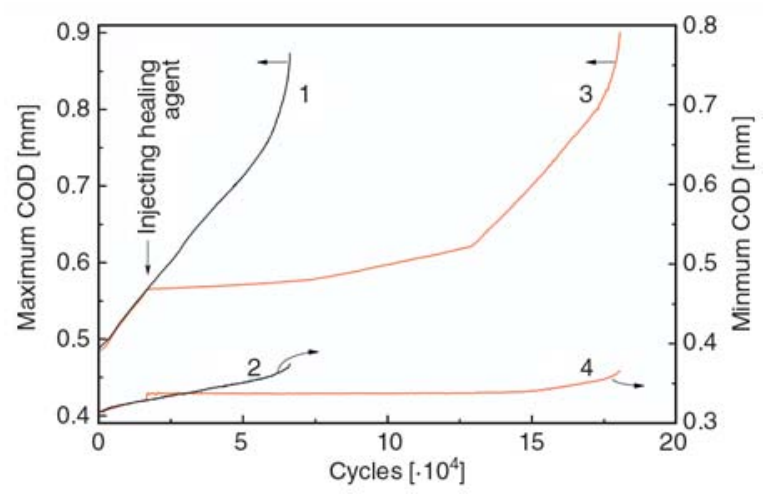

Figure 6. Maximum and minimum CODs vs. fatigue cycles of $(1,2)$ control fatigue specimens and $(3,4)$ fatigue specimens with manual injection of pre-mixed healing agent in static infiltration fashion. The applied constant stress intensity for holding crack open after the injection: $0.112 \mathrm{MPa} \cdot \mathrm{m}^{1 / 2}$. The steady-state healing time: 10 min. Testing conditions:

$K_{\max }=0.504 \mathrm{MPa} \cdot \mathrm{m}^{1 / 2}, K_{\min }=0.050 \mathrm{MPa} \cdot \mathrm{m}^{1 / 2}$, $\Delta K_{I}=0.454 \mathrm{MPa} \cdot \mathrm{m}^{1 / 2}, R=0.1$.

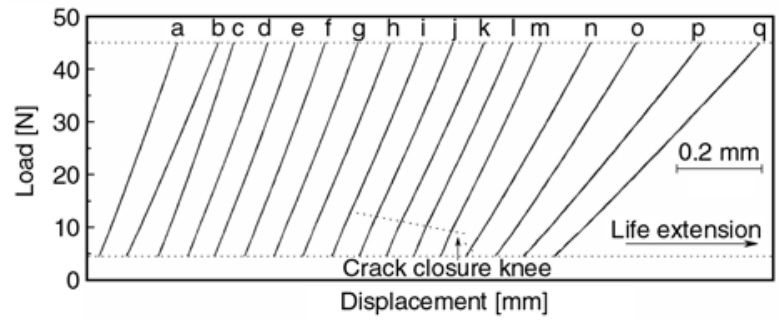

Figure 7. Load-displacement relationships measured during selected cycles of curve 3 in Figure 4. Number of the fatigue cycles and the time after the manual infiltration of pre-mixed healing agent: (a) 3000; (b) 9000 ; (c) $19200,10^{\prime}$; (d) 69600 ;

(e) $71700,185^{\prime}$; (f) 73500 ; (g) 85 500;

(h) 95700 ; (i) 105600 ; (j) 115 500, 331';

(k) 125 700; (l) $129000,376^{\prime}$; (m) 132 900;

(n) 140 100; (o) 150 000, 446'; (p) 170 800; and (q) $181800,552^{\prime}$. The applied constant stress intensity for holding crack open after the injection: $0.112 \mathrm{MPa} \cdot \mathrm{m}^{1 / 2}$. The steady-state healing time: $10 \mathrm{~min}$. Testing conditions:

$K_{\text {max }}=0.504 \mathrm{MPa} \cdot \mathrm{m}^{1 / 2}, K_{\min }=0.050 \mathrm{MPa} \cdot \mathrm{m}^{1 / 2}$, $\Delta K_{I}=0.454 \mathrm{MPa} \cdot \mathrm{m}^{1 / 2}, R=0.1$.

trated epoxy healing agent bonds the crack surfaces together and starts to transfer tensile stress across the crack faces. The adhesive firstly fails on the tension part of the load cycle by cracking in the area that experiences the highest strain amplitude [11]. This is reflected by the turning point at about 71700 cycles on the fatigue cycles dependences of crack length and maximum COD (refer to curve 3 in Figure 4 and Figure 6), from which the crack begins to advance fast. At this point, the crack advances about $1.4 \mathrm{~mm}$. A stable pre-crack process seems to be formed. At about 115500 cycles with fast crack advance, the load-displacement curve becomes clearly bimodal (curve $\mathrm{j}$ in Figure 7), representing the crack closure mechanism proposed by Elber [29]. The knee of the load-displacement curve corresponds to the open crack condition and the portion of the cyclic load experienced by the crack tip. Figure 7 further exhibits that the curve above the knee is increasingly compliant due to progressive cohesive failure of the cured healing agent (Figure 8). In contrast, the curve below the knee, which is related to the closed crack condition, retains a compliance corresponding to the epoxy wedge geometry. In the case that the cyclic stress intensity is lower than the applied constant stress intensity during healing, the infiltrated material acts as a wedge to transfer compressive stress between the crack faces. The extent to which the crack-tip 


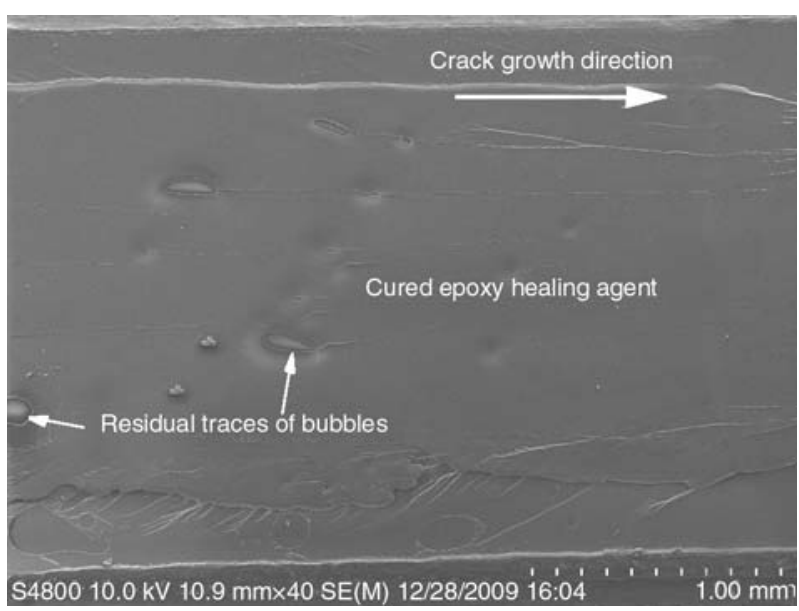

Figure 8. SEM micrograph of fatigue fracture specimen with manual injection of pre-mixed healing agent in static infiltration fashion. The applied constant stress intensity for holding crack open after the injection: $0.112 \mathrm{MPa} \cdot \mathrm{m}^{1 / 2}$. The steadystate healing time: $10 \mathrm{~min}$. Testing conditions: $K_{\text {max }}=0.504 \mathrm{MPa} \cdot \mathrm{m}^{1 / 2}, K_{\min }=0.050 \mathrm{MPa} \cdot \mathrm{m}^{1 / 2}$, $\Delta K_{I}=0.454 \mathrm{MPa} \cdot \mathrm{m}^{1 / 2}, R=0.1$.

could be unloaded is limited and hence higher $\Delta K_{\text {eff }}$ is maintained. Since cured epoxy material has very low deformation in compression and cannot be easily fragmented or otherwise dislodged from the crack, this is a potent crack retarding mechanism. Even when the adhesive wedge is damaged and the crack tip advances into the parent epoxy matrix beyond the region of the wedge, some benefit still remains from the wedging effect.

When fatigue cycles approach 129000 , the crack grows to the end of the cured epoxy wedge, and crack growth rate suddenly accelerates by 3.4 -fold from $8.3 \cdot 10^{-5}$ to $3.7 \cdot 10^{-4} \mathrm{~mm} /$ cycle. Particularly large turning points appear on the curves of crack length and maximum COD vs. fatigue cycles (refer to curve 3 in Figure 4 and Figure 6). This is because the fracture toughness of the cured healing agent is higher than that of the epoxy matrix [20], and fatigue crack has to advance slowly within the wedge region. In the meantime, knee points are observed at decreasing loads (refer to curves $j-n$ in Figure 7), indicating an increase in the effective cyclic stress intensity at the crack tip. As the crack grows past the wedge from the cured healing agent (refer to curve o in Figure 7), the crack growth rate increases with a rise in $\Delta K_{\text {eff }}$ approaching the rate before healing until failure of the specimen.

In previous studies, the adhesive infiltrants were generally allowed to be fully cured to form solid polymeric wedges under constant holding loads before resuming fatigue tests $[4,9-16]$. Here the influence of the curing of the healing agent on fatigue crack growth is taken into consideration for evaluating the role of the wedge performance. For this purpose, as mentioned in the Experimental, 10 seconds after the pre-mixed healing agent was injected into the crack plane, the fatigue test was interrupted and the crack held open at a constant stress intensity of $0.504 \mathrm{MPa} \cdot \mathrm{m}^{1 / 2}$. Fatigue loading was reestablished after different steady-state healing times of $3^{\prime}, 4^{\prime}, 5^{\prime}, 5^{\prime} 30^{\prime \prime}, 5^{\prime} 35^{\prime \prime}, 5^{\prime} 45^{\prime \prime}, 6^{\prime}, 6^{\prime} 30^{\prime \prime}$, $7^{\prime}, 8^{\prime}, 10^{\prime}, 15^{\prime}$ and $30^{\prime}$ (the single and double quotation marks represent minute and second, respectively).

Figures 9 and 10 give the typical crack length vs. fatigue cycles curves and the relationship between healing efficiency and steady-state healing time, respectively. The results indicate that healing agent hardly takes effect within the steady-state healing time range of $3^{\prime}-5^{\prime} 35^{\prime \prime}$ (refer to curves 2 and 3 in Figure 9), so that the healing efficiency is only about $12-15 \%$ (Figure 10). When the steady-state healing time reaches $5^{\prime} 45^{\prime \prime}$ and $6^{\prime}$, however, the healing efficiency is greatly increased to 302 and $1473 \%$, respectively. The crack retardation behavior is similar to that of the specimen healed at $0.112 \mathrm{MPa} \cdot \mathrm{m}^{1 / 2}$ for $10 \mathrm{~min}$ (refer to curve 3 in Figure 4). In the case that the steady-state healing time is not less than $6^{\prime} 30^{\prime \prime}$, crack can hardly advance

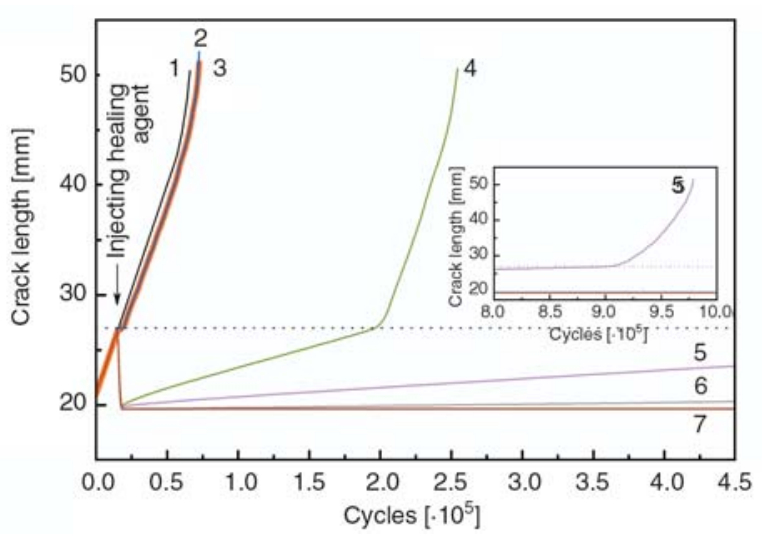

Figure 9. Crack length vs. fatigue cycles of (1) control fatigue specimen and (2-7) fatigue specimens with manual injection of pre-mixed healing agent in static infiltration fashion. The steadystate healing time: (2) $3^{\prime}$, (3) $5^{\prime} 35^{\prime \prime}$, (4) $5^{\prime} 45^{\prime \prime}$, (5) $6^{\prime}$, (6) 6 630', and (7) 8'. The applied constant stress intensity for holding crack open after the injection: $0.504 \mathrm{MPa} \cdot \mathrm{m}^{1 / 2}$. Testing conditions: $K_{\max }=0.504 \mathrm{MPa} \cdot \mathrm{m}^{1 / 2}, K_{\min }=0.050 \mathrm{MPa} \cdot \mathrm{m}^{1 / 2}$, $\Delta K_{I}=0.454 \mathrm{MPa} \cdot \mathrm{m}^{1 / 2}, R=0.1$. 


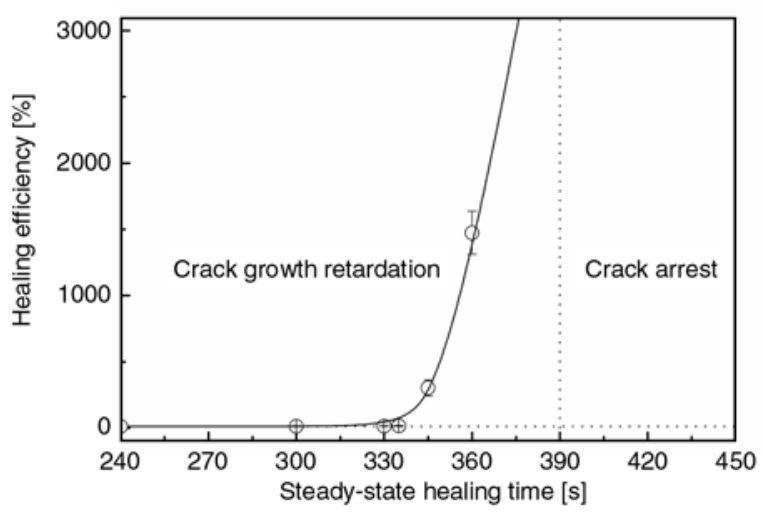

Figure 10. Healing efficiency of fatigue specimens with manual injection of pre-mixed healing agent in static infiltration fashion vs. the steady-state healing time (during which crack held open). The data are calculated using the results in Figure 9 .

after more than $10^{7}$ fatigue cycles and is considered to be fully arrested. Similarly, this time can be regarded as the critical threshold to distinguish fatigue crack growth retardation from crack arrest (Figure 10).

The above phenomena are closely related to the curing process of the epoxy based healing agent. During curing of the healing agent, the system transforms from low molecular liquid mixture into three dimensional cross-linked macromolecular networks. Molecular dynamics and macroscopic behavior of the material drastically change in the meantime [30]. Early study on curing kinetics demonstrated that the viscosity of the healing agent slowly increased in the beginning 5 min after mixing, and then rapidly increased until it gelled within

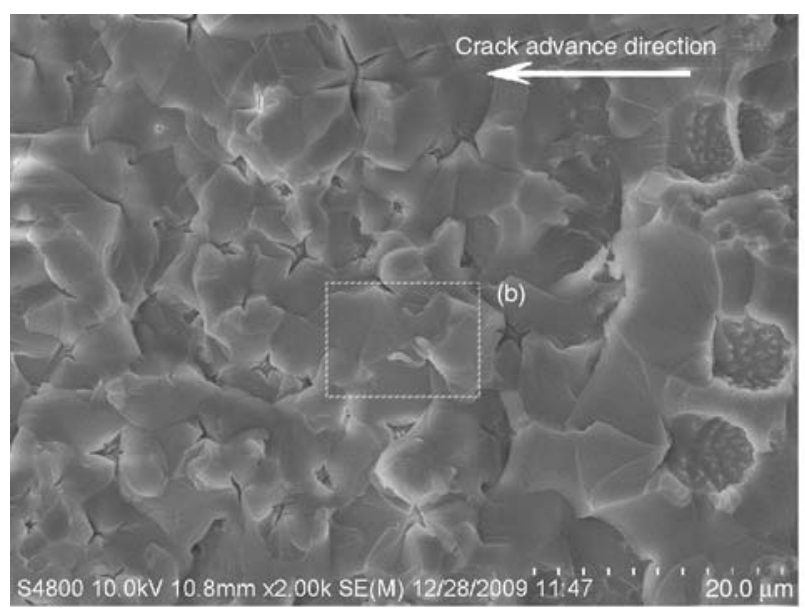

a)

Figure 12. SEM micrographs of the fractured surface of a TDCB specimen with manual injection of pre-mixed healing agent for determination of $K_{I C}$ of the cured healing agent (see the Experimental for more details). The healing agent was allowed to be cured for $9^{\prime} 20^{\prime \prime}$ and then the specimen was tested to falure within $5 \mathrm{sec}$ at a rate of displacement of $3 \mathrm{~mm} / \mathrm{min}$.

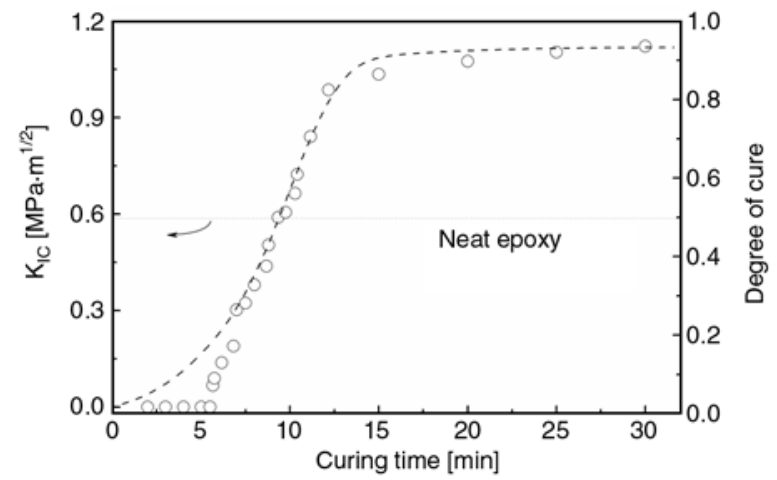

Figure 11. Curing time dependences of $K_{I C}$ (circles) and degree of cure (dash line) of the healing agent. The horizontal dotted line represents $K_{I C}$ of the epoxy matrix. $K_{I C}$ values of the healing agent were obtained from monotonic fracture tests performed at prescribed times. The data of degree of cure were estimated from isothermal polymerization of the healing agent conducted in DSC at $25^{\circ} \mathrm{C}$.

about one minute [20,21]. The gelation of the healing agent is essentially a rapid formation and increase process of hardness and adhesive strength (Figure 11). Although nearly no adhesion can be detected at a time less than $5.5 \mathrm{~min}$, fracture toughness of the healing agent sharply increases within $5^{\prime} 40^{\prime \prime}$ and $12^{\prime}$, and exceeds that of the epoxy matrix at about $9^{\prime}$. Obviously, the increase in $K_{I C}$ keeps in step with the degree of cure of the healing agent, as shown by Brown et al. [5]. In this context, development of fatigue crack might become rather difficult when the steady-state healing time is longer than $9^{\prime}$. The deduction is confirmed by the fact that very few tearing marks appear at the initial phase of the

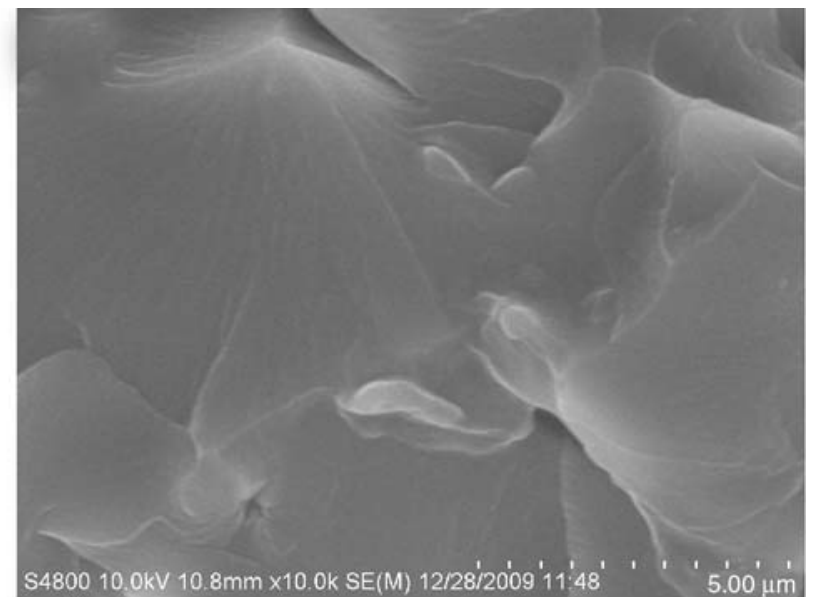

b) 
fatigue crack (figure omitted). Obvious tearing traces are found on the fast fracture plane when the healing agent is in the rubbery state (Figure 12). Accordingly, evident retardation effect is obtained for the steady-state healing time from $5^{\prime} 45^{\prime \prime}$ to $6^{\prime}$.

\subsection{Effect of applied range of cyclic stress intensity revealed by dynamic infiltration tests}

The works by other researchers have shown that the in-situ retardation and arrest of fatigue crack are closely related to the applied range of cyclic stress intensity, $\Delta K_{I}[5-8]$. To check whether this rule is also valid for the current healing system, the fatigue experiments associated with dynamic infiltration were conducted at different $\Delta K_{I}$ values by changing the maximum cyclic stress intensity $K_{\max }$ between 0.336 and $0.560 \mathrm{MPa} \cdot \mathrm{m}^{1 / 2}$ at constant stress ratio of $R=0.1$, and by changing the stress ratio $R$ from 0.05 to 0.6 at constant $K_{\max }=0.504 \mathrm{MPa} \cdot \mathrm{m}^{1 / 2}$.

As shown in Figures 13-15, fatigue crack is retarded by the infiltrated healing agent following the injection. The lower the maximum cyclic stress intensity (or the higher stress ratio), the more evident the retardation effect and the higher healing efficiency. Especially when the $K_{\max }$ is not more than $0.420 \mathrm{MPa} \cdot \mathrm{m}^{1 / 2}$ or the $R$ value is not less than 0.25 , crack can hardly advance for more than $10^{7}$ cycles with the gelation and solidification of the healing agent, and hence is considered to be fully arrested. During this process, the mechanisms

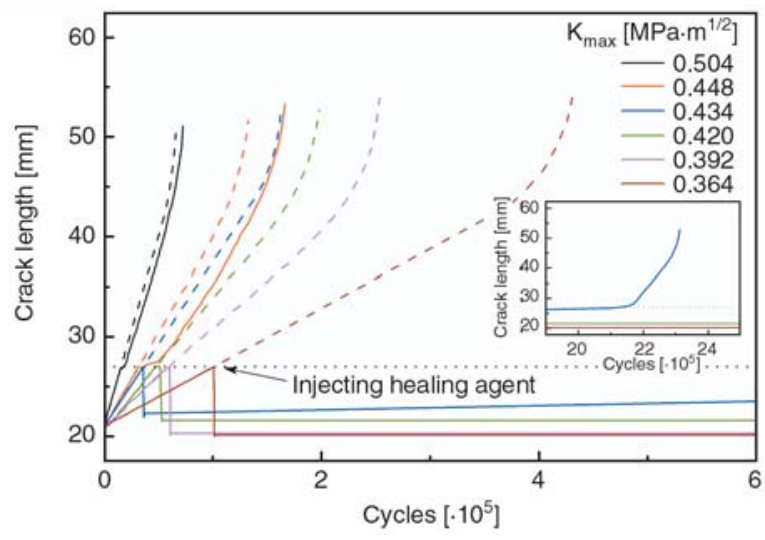

Figure 13. Crack length vs. fatigue cycles of control fatigue specimens (dash lines) and fatigue specimens with manual injection of pre-mixed healing agent in dynamic infiltration fashion (solid lines). Testing conditions: $K_{\max }=0.504$, $0.448,0.434,0.420,0.392$ and $0.364 \mathrm{MPa} \cdot \mathrm{m}^{1 / 2}$, $R=0.1$. of polymeric wedge crack-tip shielding and adhesive bonding must play the key role. In fact, reducing $K_{\max }$ or increasing $R$ is equivalent to decreasing $\Delta K_{I}$, so that $\Delta K_{\text {eff }}$ is decreased, offering improved retardation effect.

To have more information about the healing mechanism involved in the dynamic infiltration tests, the processes of crack growth retardation and crack arrest measured at two typical $K_{\max }$ values (i.e. 0.504 and $0.420 \mathrm{MPa} \cdot \mathrm{m}^{1 / 2}$ ) are analyzed in the following.

Immediately after the injection, the fluidic healing agent rapidly flows throughout the cracked plane and penetrates into the crack tip under cycling load. The rate of crack growth decreases to a lower value. Similar to the cases discussed in the last subsections, full opening and closing of crack at the maximum and minimum loads are hindered accord-

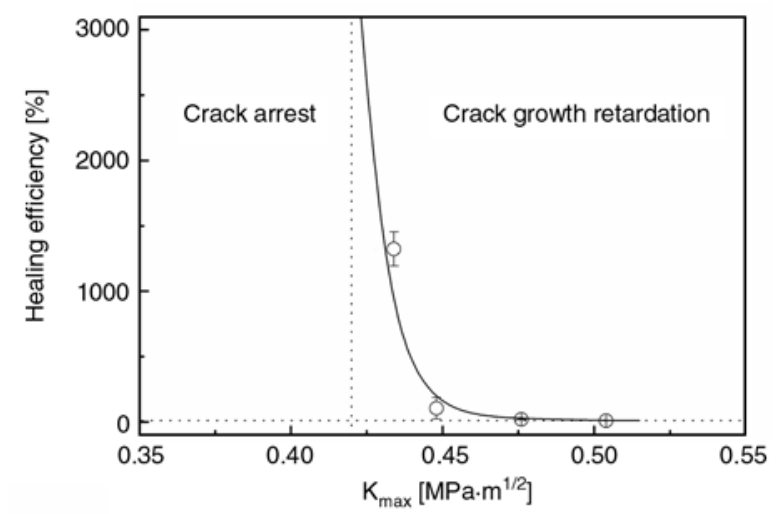

Figure 14. Healing efficiency of fatigue specimens with manual injection of pre-mixed healing agent in dynamic infiltration fashion vs. maximum cyclic stress intensity. The data are calculated using the results in Figure 13.

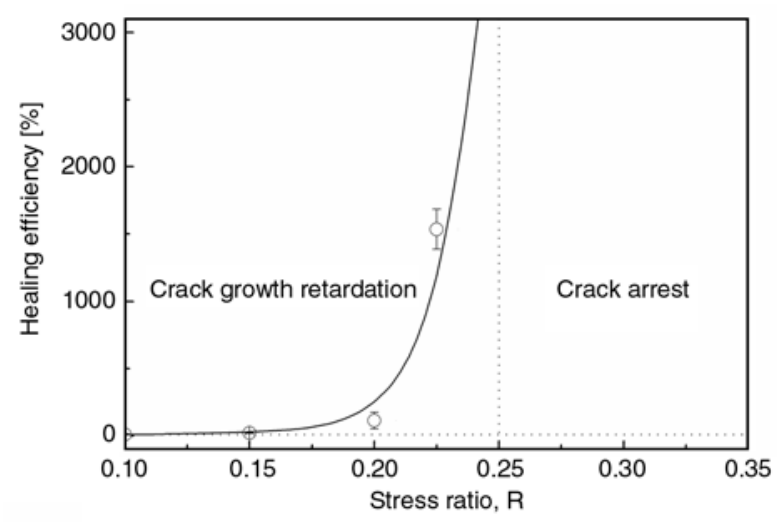

Figure 15. Healing efficiency of fatigue specimens with manual injection of pre-mixed healing agent in dynamic infiltration fashion vs. cyclic stress intensity ratio. The data are calculated using the results in Figure 13. 


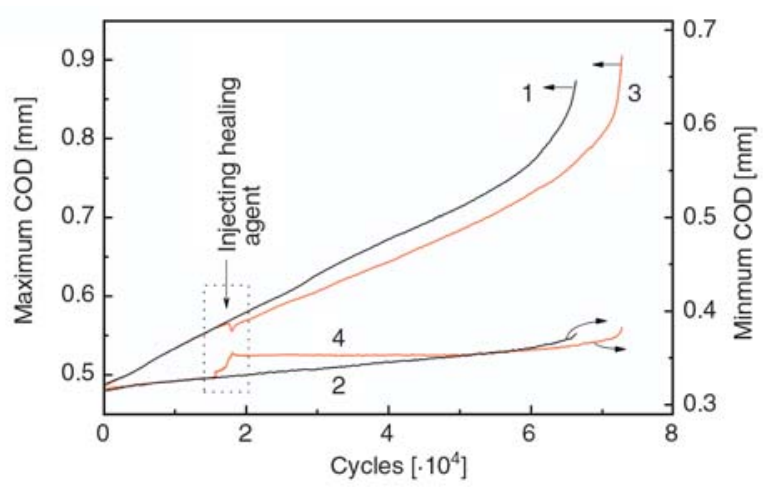

Figure 16. Maximum and minimum CODs vs. fatigue cycles of $(1,2)$ control fatigue specimens and $(3,4)$ fatigue specimens with manual injection of pre-mixed healing agent in dynamic infiltration fashion. Testing conditions:

$K_{\max }=0.504 \mathrm{MPa} \cdot \mathrm{m}^{1 / 2}, K_{\min }=0.050 \mathrm{MPa} \cdot \mathrm{m}^{1 / 2}$, $\Delta K_{I}=0.454 \mathrm{MPa} \cdot \mathrm{m}^{1 / 2}, R=0.1$.

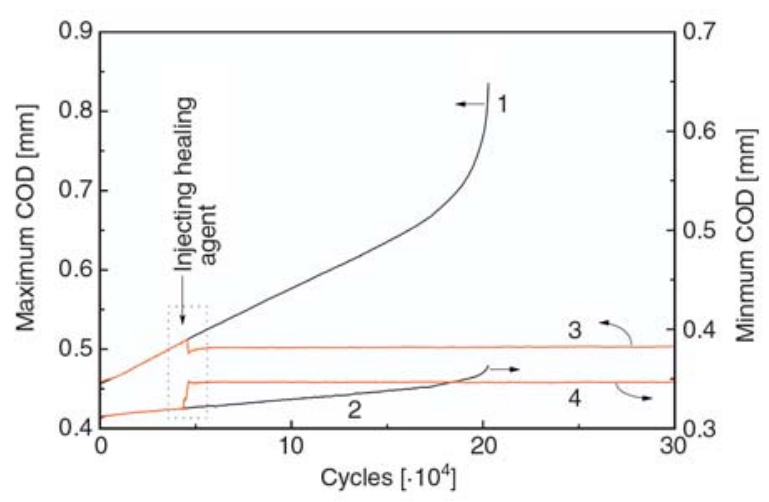

Figure 17. Maximum and minimum CODs vs. fatigue cycles of $(1,2)$ control fatigue specimens and $(3,4)$ fatigue specimens with manual injection of pre-mixed healing agent in dynamic infiltration fashion. Testing conditions:

$K_{\max }=0.420 \mathrm{MPa} \cdot \mathrm{m}^{1 / 2}, K_{\min }=0.042 \mathrm{MPa} \cdot \mathrm{m}^{1 / 2}$, $\Delta K_{I}=0.378 \mathrm{MPa} \cdot \mathrm{m}^{1 / 2}, R=0.1$.

ingly, so that fluctuations appear on the fatigue cycles dependence of the maximum and minimum CODs (Figures 16-19). Hysteresis loops are also observed on the load-displacement curves (refer curve d in Figure 20 and Figure 21). On the basis of the study in the sub-section 3.1, it is known that hydrodynamic pressure crack-tip shielding mechanism should be the main contributor to the crack retardation within the beginning $\sim 5.5 \mathrm{~min}$. Combining with the results of static infiltration tests with steady-state healing time of $3^{\prime}-5^{\prime} 35^{\prime \prime}$ (refer to curves 2 and 3 in Figure 9), we can conclude that the stress status of crack has no influence on crack growth retardation basically before the healing agent gels.

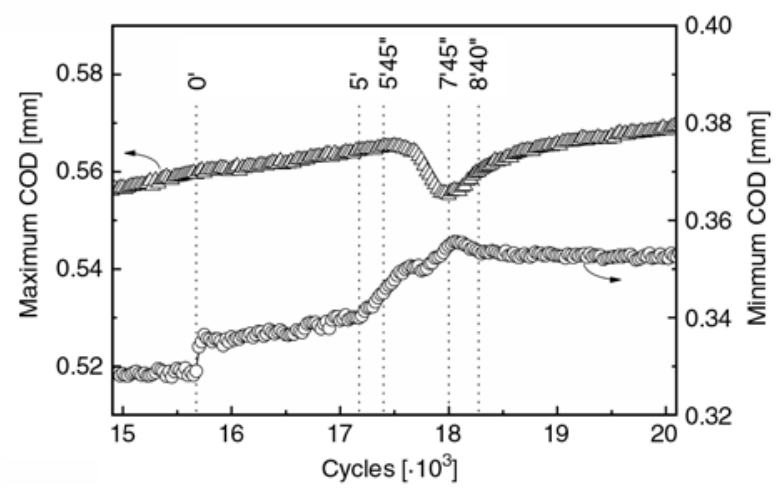

Figure 18. Maximum and minimum CODs vs. fatigue cycles of fatigue specimens with manual injection of pre-mixed healing agent in dynamic infiltration fashion (partial magnification of curves 3 and 4 within the dotted frame in Figure 16). $0^{\prime}$ means the time when the epoxy prepolymer is injected. Testing conditions: $K_{\max }=0.504 \mathrm{MPa} \cdot \mathrm{m}^{1 / 2}, K_{\min }=0.050 \mathrm{MPa} \cdot \mathrm{m}^{1 / 2}$, $\Delta K_{I}=0.454 \mathrm{MPa} \cdot \mathrm{m}^{1 / 2}, R=0.1$.

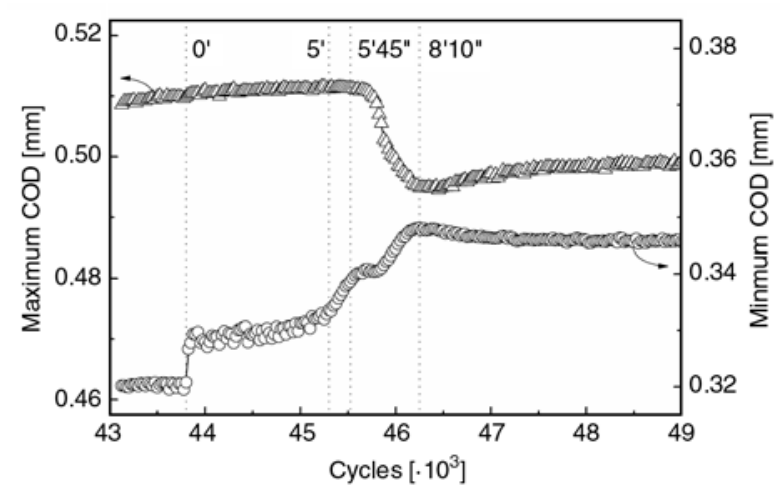

Figure 19. Maximum and minimum CODs vs. fatigue cycles of fatigue specimens with manual injection of pre-mixed healing agent in dynamic infiltration fashion (partial magnification of curves 3 and 4 within the dotted frame in Figure 17). $0^{\prime}$ means the time when the epoxy prepolymer is injected. Testing conditions: $K_{\max }=0.420 \mathrm{MPa} \cdot \mathrm{m}^{1 / 2}, K_{\min }=0.042 \mathrm{MPa} \cdot \mathrm{m}^{1 / 2}$, $\Delta K_{I}=0.378 \mathrm{MPa} \cdot \mathrm{m}^{1 / 2}, R=0.1$.

Along with the abrupt increase in viscosity and gelation as of $\sim 5.5 \mathrm{~min}$ (Figure 11), the healing agent rapidly changes from liquid to rubbery state. Its bonding capability forms and begins to take effect. The maximum and minimum CODs are further constrained with a regression of the crack tip (Figures 18 and 19). They reach the extreme values at $7^{\prime} 45^{\prime \prime}$ for $K_{\max }=0.504 \mathrm{MPa} \cdot \mathrm{m}^{1 / 2}$ and at $8^{\prime} 10^{\prime \prime}$ for $K_{\max }=0.420 \mathrm{MPa} \cdot \mathrm{m}^{1 / 2}$, respectively. Afterwards, the increase in the maximum COD for $K_{\max }=$ $0.504 \mathrm{MPa} \cdot \mathrm{m}^{1 / 2}$ with fatigue cycles becomes steady, meaning that the closed crack can be quickly 
opened (refer to curve 3 in Figure 16, and Figure 18). With respect to the minimum COD for $K_{\max }=0.504 \mathrm{MPa} \cdot \mathrm{m}^{1 / 2}$, it quickly declines to a plateau (refer to curve 4 in Figure 16 and Figure 18) owing to the formation of a stable wedge. In the case that $K_{\max }=0.420 \mathrm{MPa} \cdot \mathrm{m}^{1 / 2}$, however, the results are not completely the same. The maximum COD slightly increases and then becomes nearly invariable with fatigue cycles (refer to curve 3 in Figure 17 and Figure 19). This corresponds to the fact that the closed crack advances for a very short distance before it is fully arrested. In contrast, the variation in the minimum COD resembles that at $K_{\max }=0.504 \mathrm{MPa} \cdot \mathrm{m}^{1 / 2}$ as characterized by the appearance of a plateau (refer to curve 4 in Figure 17 and Figure 19) because of the newly established cured epoxy wedge.

It is worth noting that in the course of hardening of the healing agent, the opening degree of the hysteresis loops gradually increases and the maximum open position constantly moves upward (refer to curves $f-j$ in Figure 20, and curves $f-n$ in Figure 21). The former reaches the maximum at about $8^{\prime}$ for $K_{\max }=0.504 \mathrm{MPa} \cdot \mathrm{m}^{1 / 2}$ and at $7^{\prime} 20^{\prime \prime}$ for $K_{\max }=0.420 \mathrm{MPa} \cdot \mathrm{m}^{1 / 2}$, as shown in curve k in Figure 20 and Figure 21, respectively. Then, it gradu-

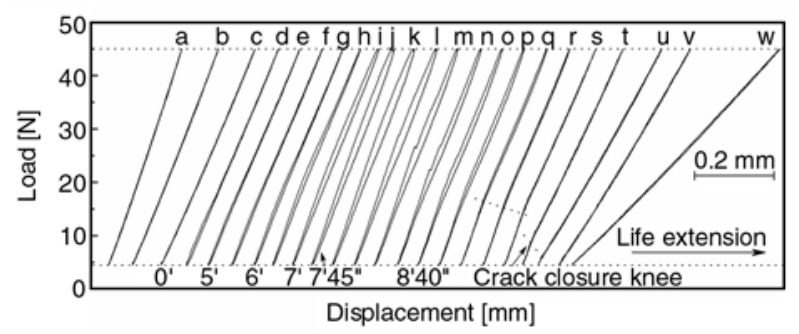

Figure 20. Load-displacement relationships measured during selected cycles in Figures 16 and 18. Number of the fatigue cycles and the time after the manual infiltration of pre-mixed healing agent:

(a) 17 400; (b) 23 400; (c) 15 675, 0';

(d) $15825,30^{\prime \prime} ;$ (e) $17175,5^{\prime}$; (f) 17325 ,

5'30"; (g) 17 475, 6'; (h) 17 625, 6'30";

(i) $17775,7^{\prime}$; (j) $18000,7^{\prime} 45^{\prime \prime} ;$; (k) $18075,8^{\prime}$;

(l) $18125,8^{\prime} 10^{\prime \prime} ;$ (m) $18175,8^{\prime} 20^{\prime \prime}$;

(n) $18225,8^{\prime} 30^{\prime \prime}$; (o) $18275,8^{\prime} 40^{\prime \prime}$;

(p) $18375,9^{\prime}$; (q) $18675,10^{\prime}$; (r) $18975,11^{\prime}$; (s) 22 400; (t) 30 000; (u) 45 000; (v) 49 950; and $(\mathrm{w}) 72750.0^{\prime}$ means the time when the pre-mixed healing agent is injected. Testing conditions: $K_{\max }=0.504 \mathrm{MPa} \cdot \mathrm{m}^{1 / 2}$,

$K_{\min }=0.050 \mathrm{MPa} \cdot \mathrm{m}^{1 / 2}, \Delta K_{I}=0.454 \mathrm{MPa} \cdot \mathrm{m}^{1 / 2}$, $R=0.1$.

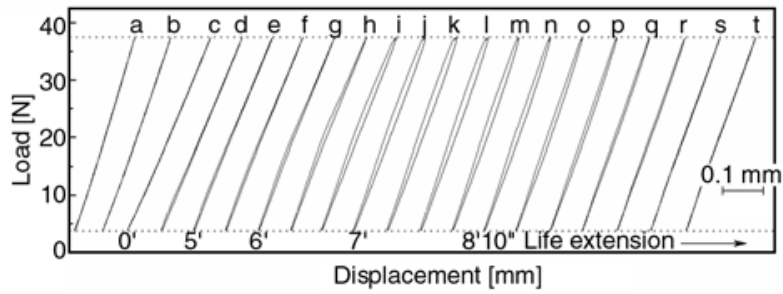

Figure 21. Load-displacement relationships measured during selected cycles in Figures 17 and 19. Number of the fatigue cycles and the time after the manual infiltration of pre-mixed healing agent: (a) 3000; (b) 30 000; (c) $43800,0^{\prime}$; (d) 43 950, $30^{\prime \prime}$; (e) $45300,5^{\prime}$; (f) $45450,5^{\prime} 30^{\prime \prime}$;

(g) $45600,6^{\prime}$; (h) 45 725, 6'25"; (i) 45800 , 6'40"; (j) 45 900, 7'; (k) 46 000, 7'20";

(l) 46 100, 7'40"; (m) 46 200, 8'; (n) 46250 , 8'10"; (o) 46 350, 8'30"; (p) 46 500, 9'; (q) $46800,10^{\prime}$; (r) $47100,11^{\prime}$; (s) 53 100; and (t) $6 \cdot 10^{8} .0^{\prime}$ means the time when the premixed healing agent is injected. Testing conditions: $K_{\max }=0.420 \mathrm{MPa} \cdot \mathrm{m}^{1 / 2}$,

$K_{\min }=0.042 \mathrm{MPa} \cdot \mathrm{m}^{1 / 2}, \Delta K_{I}=0.378 \mathrm{MPa} \cdot \mathrm{m}^{1 / 2}$, $R=0.1$.

ally decreases until disappearance at about $11^{\prime}$ (refer to curves k-r in Figure 20 and Figure 21). Clearly, within the time range from $5.5^{\prime}$ to $11^{\prime}$, the visco-elastic damping provided by the healing agent increases and then decreases with the gradual increase in crosslinking of the healing agent. The increase in the maximum open position is attributed to the fact that trigger of the hysteresis in terms of lower tension or pressure becomes increasingly difficult. When the curing of the healing agent is almost completed, the hysteresis loop disappears (refer to curve $r$ in Figure 20 and Figure 21). Especially for $K_{\max }=0.504 \mathrm{MPa} \cdot \mathrm{m}^{1 / 2}$, the knee on the load-displacement curves gradually forms from about $8^{\prime} 10^{\prime \prime}$ to $11^{\prime}$ (refer to curves 1-r in Figure 20) as a result of crack closure [15]. Nevertheless, when $K_{\max }=0.420 \mathrm{MPa} \cdot \mathrm{m}^{1 / 2}$, the aforesaid knee doesn't appear on the load-displacement curves even after disappearance of the hysteresis loop (Figure 21). The slopes of the load-displacement curves (related to the compliance) hardly increase after $6 \cdot 10^{8}$ cycles (refer to curve $t$ in Figure 21), which represents that the crack is fully arrested.

On the other hand, ear-piercing sound of 'dada' was perceived as of about $8^{\prime} 40^{\prime \prime}$ during the process of crack growth for $K_{\max }=0.504 \mathrm{MPa} \cdot \mathrm{m}^{1 / 2}$, but never for $K_{\max }=0.420 \mathrm{MPa} \cdot \mathrm{m}^{1 / 2}$. It should come from (i) tearing of the curing adhesive in the process of crack opening and advancing, and (ii) 
impact of torn surfaces in the process of crack closing after growth of fatigue crack through cured adhesive to the original crack tip position. The phenomenon proves the events of crack advancing or crack growth retardation from another angle.

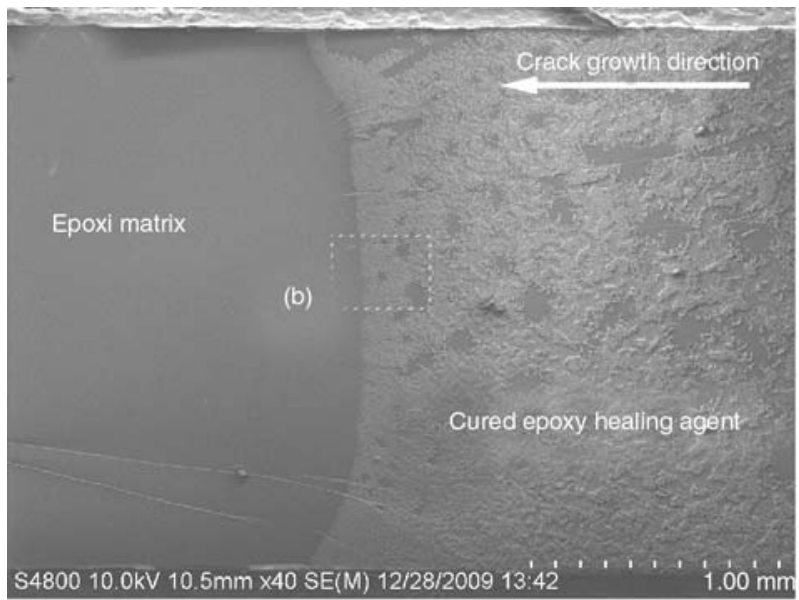

a)

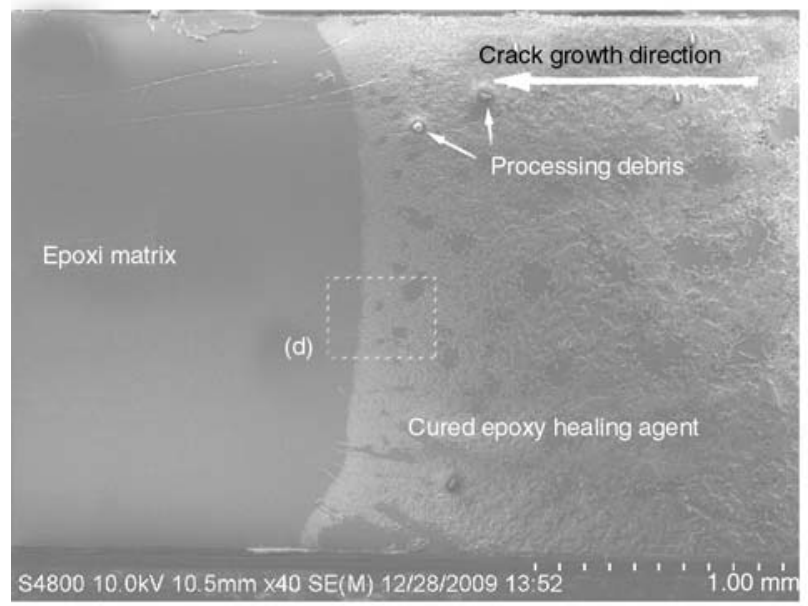

c)

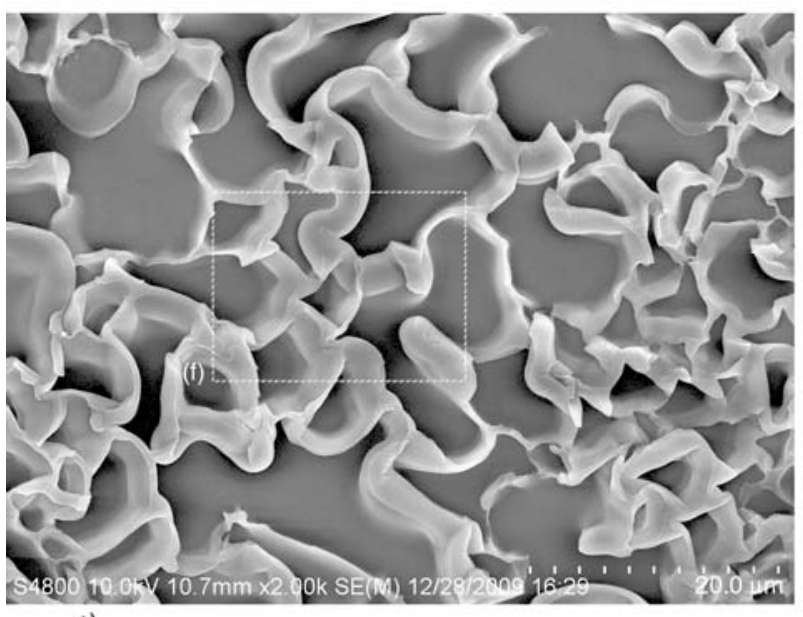

e)
Morphology of the fatigue fracture surfaces can further explain the crack healing process (Figures 22 and 23). The cured healing agent is symmetrically distributed on the two opposite planes of fatigue crack (Figures 22a-d). This result indicates

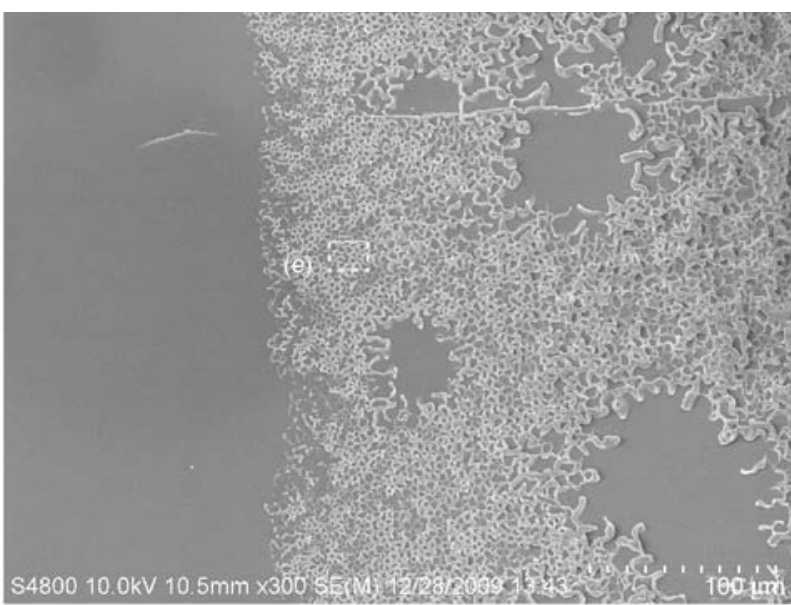

b)

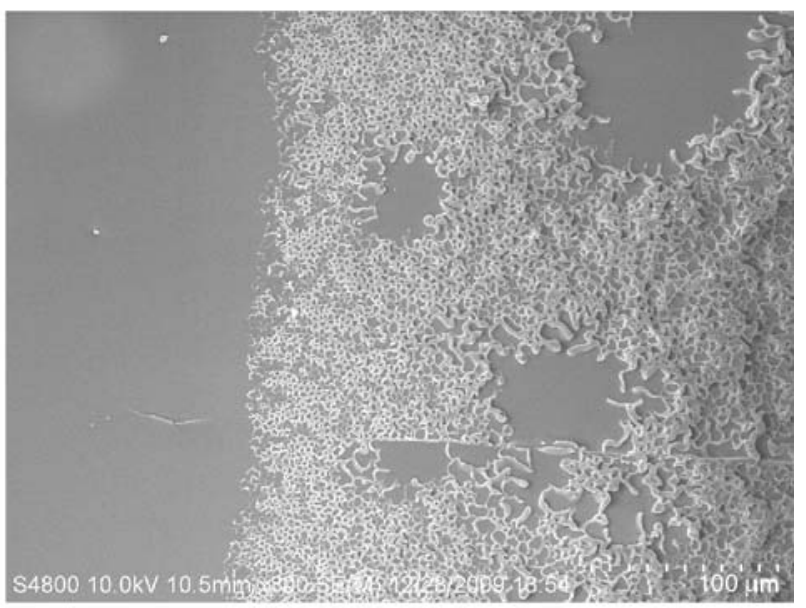

d)

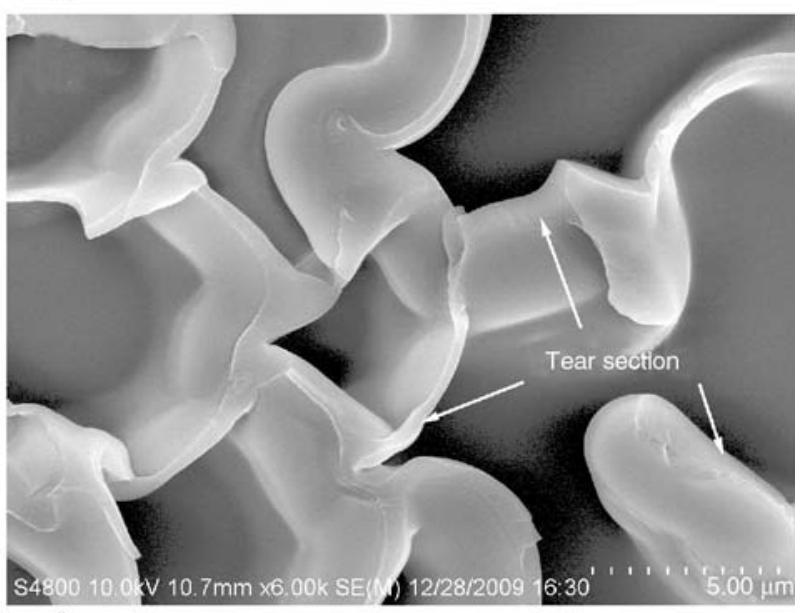

f)

Figure 22. SEM micrographs of fatigue fracture surfaces of the specimen with manual injection of pre-mixed healing agent in dynamic infiltration fashion. (a) Fatigue crack plane; (b) partial magnification of (a); (c) the opposite part of (a); (d) the opposite part of (b) taken from (c); (e) partial magnification of (b); (f) partial magnification of (e). Testing conditions: $K_{\max }=0.504 \mathrm{MPa} \cdot \mathrm{m}^{1 / 2}, K_{\min }=0.050 \mathrm{MPa} \cdot \mathrm{m}^{1 / 2}, \Delta K_{I}=0.454 \mathrm{MPa} \cdot \mathrm{m}^{1 / 2}, R=0.1$. 


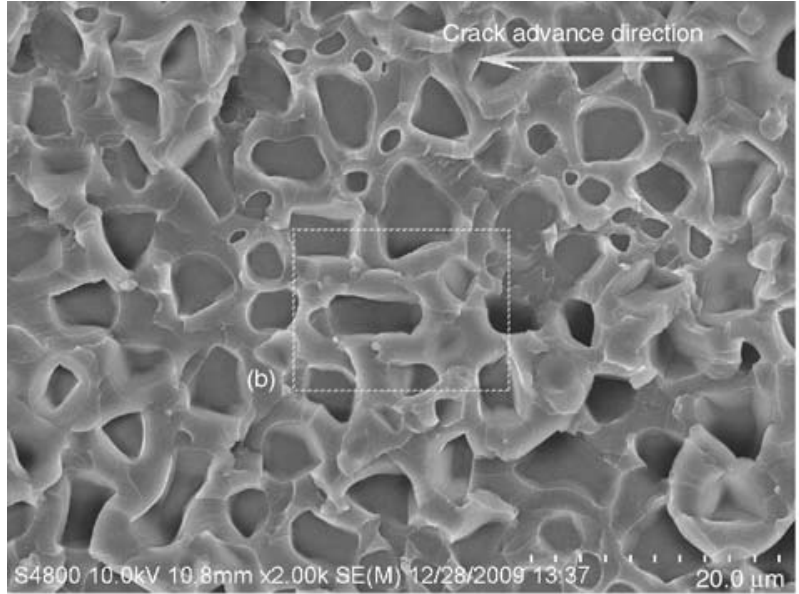

a)

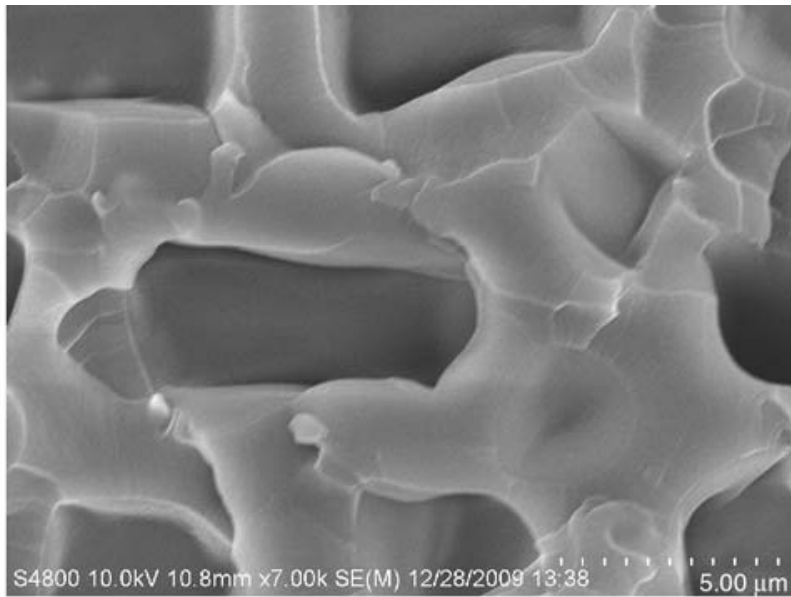

b)

Figure 23. SEM micrographs of fatigue fracture surface of the specimen with manual injection of pre-mixed healing agent in dynamic infiltration fashion. (a) Fatigue crack plane; (b) partial magnification of (a). Crack can hardly advance for $6 \cdot 10^{8}$ cycles and hence is fully arrested. The specimen was fractured at static load using a rate of displacement of $3 \mathrm{~mm} / \mathrm{min}$ without precrack. Fatigue testing conditions: $K_{\max }=0.420 \mathrm{MPa} \cdot \mathrm{m}^{1 / 2}$, $K_{\min }=0.042 \mathrm{MPa} \cdot \mathrm{m}^{1 / 2}, \Delta K_{I}=0.378 \mathrm{MPa} \cdot \mathrm{m}^{1 / 2}, R=0.1$.

that the crack propagates through the membrane formed by the cured healing agent, and cohesive failure rather than interfacial debonding occurs in the case of crack retardation. Obvious tear traces and good bonding effect of the healing agent are found on the fracture plane (Figures 22e and f). Besides, blank areas without the healing agent are also observed on the fracture plane (e.g. Figures $22 b$ and d). They originate from the air bubbles that were introduced when the liquid healing agent was subjected to the repeated extrusion under cycling loading.

When the fatigue crack is arrested at $K_{\max }=$ $0.420 \mathrm{MPa} \cdot \mathrm{m}^{1 / 2}$, the specimen is eventually fractured at static load using a displacement rate of $3 \mathrm{~mm} / \mathrm{min}$ without precrack. The maximum fracture load reaches $121 \mathrm{~N}$, which is much higher than that of the epoxy matrix $(\sim 52 \mathrm{~N})$. The cohesive failure of the cured healing agent is characterized by wider tear tapes and larger bonding area on the fracture plane (Figures 23). It implies that stronger adhesion effect is obtained at lower $K_{\max }$, which favors to arrest crack.

\section{Conclusions}

The epoxy component of the healing agent proved to act as a viscous fluid, effectively retarding fatigue crack growth in epoxy material by hydrodynamic pressure crack-tip shielding effect. Accord- ingly, the latter's fatigue life was extended by about 2.5 times.

Artificial crack closure was achieved during static infiltration tests by injecting the pre-mixed healing agent into the crack plane forming a polymer wedge at the crack tip. As a result, crack growth retardation and even permanent crack arrest were observed. Both crack-face wedging and adhesion contributed to the retardation, but the adhesive component ceased after the crack grew through the wedge to the original crack tip position. The higher the constant stress intensity applied for holding crack open after the manual infiltration, the thicker the polymerized wedge and the better the retardation effect. When the former was not less than $0.392 \mathrm{MPa} \cdot \mathrm{m}^{1 / 2}$, crack was fully arrested. Similarly, in the case that the steady-state healing time approached about 6 min after the infiltration, adhesive strength and hardness of the gelled healing agent were well developed and $\Delta K_{\text {eff }}$ was effectively reduced. Cohesive failure of the wedge occurred under cyclic loading. Further extending the steady-state healing time to $6^{\prime} 30^{\prime \prime}$, crack arrest was observed.

As for the dynamic infiltration tests, the applied stress intensity range was found to be the most influential parameter. When the pre-mixed healing agent was infiltrated into the crack plane, hydrodynamic pressure shielding mechanism firstly provided resistance to crack growth. With the rapid 
increase in viscosity of the healing agent until gelation, shielding effect resulting from the wedge and adhesive bonding gradually played the leading role. The lower the maximum cyclic stress intensity or the higher the stress ratio, the more prominent the retardation effect. The maximum cyclic stress intensity of about $0.420 \mathrm{MPa} \cdot \mathrm{m}^{1 / 2}$ and the stress ratio of about 0.25 became the watersheds between fatigue crack growth retardation and crack arrest, respectively.

The present work is the first attempt of ours towards healing fatigue crack using epoxy/mercaptan/tertiary amine system. The capability of the healing agent for retarding or arresting fatigue crack growth revealed hereinbefore demonstrates its potential for in-situ self-healing of fatigue damage. More importantly, the microscopic information helps to understand the healing mechanisms of self-healing composites with dual microencapsulated healing agent subjected to cyclic loading, and to optimize the healant formulation accordingly. In authentic self-healing composites, the appearance of the healant loaded capsules would change the intrinsic properties of the composites and deviate the propagation path of fatigue crack, which disfavors the analysis of the true healing mechanism involved.

Successful retardation and/or arrest of fatigue cracks have been observed in in-situ self-healing epoxy composites containing dual encapsulated healant, i.e. two types of microcapsules that respectively include epoxy prepolymer and mercaptan/ tertiary amine hardener. The results and analyses will be reported in another article of the authors.

\section{Acknowledgements}

The authors are grateful to the support of the Natural Science Foundation of China (Grants: U0634001, 20874117, 50573093 and 50903095) and China Postdoctoral Science Foundation.

\section{References}

[1] Murphy E. B., Wudl F.: The world of smart healable materials. Progress in Polymer Science, 35, 223-251 (2010).

DOI: $10.1016 /$ j.progpolymsci.2009.10.006
[2] Yuan Y. C., Yin T., Rong M. Z., Zhang M. Q.: Self healing in polymers and polymer composites. Concepts, realization and outlook: A review. Express Polymer Letters, 2, 238-250 (2008).

DOI: $10.3144 /$ expresspolymlett.2008.29

[3] Caruso M. M., Davis D. A., Shen Q., Odom S. A., Sottos N. R., White S. R., Moore J. S.: Mechanicallyinduced chemical changes in polymeric materials. Chemical Reviews, 109, 5755-5798 (2009). DOI: $10.1021 / \mathrm{cr} 9001353$

[4] Brown E. N., White S. R., Sottos N. R.: Retardation and repair of fatigue cracks in a microcapsule toughened epoxy composite - Part I: Manual infiltration. Composites Science and Technology, 65, 2466-2473 (2005).

DOI: 10.1016/j.compscitech.2005.04.020

[5] Brown E. N., White S. R., Sottos N. R.: Retardation and repair of fatigue cracks in a microcapsule toughened epoxy composite - Part II: In situ self-healing. Composites Science and Technology, 65, 2474-2480 (2005).

DOI: $10.1016 /$ j.compscitech.2005.04.053

[6] Jones A. S., Rule J. D., Moore J. S., Sottos N. R., White S. R.: Life extension of self-healing polymers with rapidly growing fatigue cracks. Journal of the Royal Society Interface, 4, 395-403 (2007). DOI: 10.1098/rsif.2006.0199

[7] Maiti S., Geubelle P. H.: Cohesive modeling of fatigue crack retardation in polymers: Crack closure effect. Engineering Fracture Mechanics, 73, 22-41 (2006).

DOI: 10.1016/j.engfracmech.2005.07.005

[8] Maiti S., Shankar C., Geubelle P. H., Kieffer J.: Continuum and molecular-level modeling of fatigue crack retardation in self-healing polymers. Journal of Engineering Materials and Technology-Transactions of the ASME, 128, 595-602 (2006).

DOI: $10.1115 / 1.2345452$

[9] James M. N., Smith G. C.: Surface microcrack closure in fatigue: A comparison of compliance and crack sectioning data. International Journal of Fracture, 22, R69-R75 (1983). DOI: $10.1007 / \mathrm{BF} 00942729$

[10] Shin C. S., Wang C. M., Song P. S.: Fatigue damage repair: A comparison of some possible methods. International Journal of Fatigue, 18, 535-546 (1996). DOI: $\underline{10.1016 / \mathrm{S} 0142-1123(96) 00029-1}$

[11] Sharp P. K., Clayton J. Q., Clark G.: Retardation and repair of fatigue cracks by adhesive infiltration. Fatigue and Fracture of Engineering Materials and Structures, 20, 605-614 (1997). DOI: 10.1111/j.1460-2695.1997.tb00292.x

[12] Song P. S., Hwang S., Shin C. S.: Effect of artificial closure materials on crack growth retardation. Engineering Fracture Mechanics, 60, 47-58 (1998). DOI: $\underline{10.1016 / \mathrm{S} 0013-7944(97) 00180-\mathrm{X}}$ 
[13] Shin C. S., Cai C. Q.: Surface fatigue crack growth suppression in cylindrical rods by artificial infiltration. International Journal of Fatigue, 30, 560-567 (2008).

DOI: $10.1016 /$ j.ijfatigue.2007.03.005

[14] ur-Rehman A., Thomason P. F.: The effect of artificial fatigue-crack closure on fatigue-crack growth. Fatigue and Fracture of Engineering Materials and Structures, 16, 1081-1090 (1993). DOI: 10.1111/j.1460-2695.1993.tb00079.x

[15] Shin C. S., Chen Z. Z.: Fatigue life extension by electroless nickel infiltration plating. International Journal of Fatigue, 23, 777-788 (2001). DOI: $\underline{10.1016 / \mathrm{S} 0142-1123(01) 00038-X}$

[16] Wang Y., Zho M., Feng D.: A study of retarding fatigue crack growth using an artificial wedge. Fatigue and Fracture of Engineering Materials and Structures, 16, 363-376 (1993). DOI: 10.1111/j.1460-2695.1993.tb00093.x

[17] White S. R., Sottos N. R., Geubelle P. H., Moore J. S., Kessler M. R., Sriram S. R., Brown E. N., Viswanathan S.: Autonomic healing of polymer composites. Nature, 409, 794-797 (2001).

DOI: $\underline{10.1038 / 35057232}$

[18] Yuan Y. C., Rong M. Z., Zhang M. Q.: Preparation and characterization of microencapsulated polythiol. Polymer, 49, 2531-2541 (2008). DOI: $10.1016 /$ j.polymer.2008.03.044

[19] Yuan Y. C., Rong M. Z., Zhang M. Q.: Preparation and characterization of poly (melamine-formaldehyde) walled microcapsules containing epoxy. Acta Polymerica Sinica, 5, 472-480 (2008).

[20] Yuan Y. C., Rong M. Z., Zhang M. Q., Chen J., Yang G. C., Li X. M.: Self-healing polymeric materials using epoxy/mercaptan as the healant. Macromolecules, 41, 5197-5202 (2008). DOI: $10.1021 / \mathrm{ma} 800028 \mathrm{~d}$

[21] Yuan Y. C., Rong M. Z., Zhang M. Q., Yang G. C.: Study of factors related to performance improvement of self-healing epoxy based on dual encapsulated healant. Polymer, 50, 5771-5781 (2009).

DOI: $10.1016 /$ j.polymer.2009.10.019
[22] Brown E. N., Sottos N. R., White S. R.: Fracture testing of a self-healing polymer composite. Experimental Mechanics, 42, 372-379 (2002).

DOI: $10.1007 / \mathrm{BF} 02412141$

[23] Brown E. N., White S. R., Sottos N. R.: Fatigue crack propagation in microcapsule-toughened epoxy. Journal of Materials Science, 41, 6266-6273 (2006). DOI: $10.1007 / \mathrm{s} 10853-006-0512-\mathrm{y}$

[24] Tzou J-L., Hsueh C. H., Evans A. G., Ritchie R. O.: Fatigue crack propagation in oil environments - II. A model for crack closure induced by viscous fluids. Acta Metallurgica, 33, 117-127 (1985). DOI: 10.1016/0001-6160(85)90225-1

[25] Davis F. H., Ellison E. G.: Hydrodynamic pressure effects of viscous fluid flow in a fatigue crack. Fatigue and Fracture of Engineering Materials and Structures, 12, 527-542 (1989). DOI: 10.1111/j.1460-2695.1989.tb00561.x

[26] Yi K. S., Cox B. N., Dauskardt R. H.: Fatigue crackgrowth behavior of materials in viscous fluid environments. Journal of the Mechanics and Physics of Solids, 47, 1843-1871 (1999). DOI: $\underline{10.1016 / \mathrm{S} 0022-5096(99) 00002-2}$

[27] Endo K., Okada T., Komai K., Kiyota M.: Fatigue crack propagation of steel in oil. Bulletin of the Japan Society of Mechanical Engineers, 15, 1316-1323 (1972).

[28] Paris P. C., Gomez M. P., Anderson W. E.: A rational analytic theory of fatigue. The Trend in Engineering, 13, 9-14 (1961).

[29] Elber W.: Fatigue crack closure under cyclic tension. Engineering Fracture Mechanics, 2, 37-45 (1970). DOI: 10.1016/0013-7944(70)90028-7

[30] Petrie E. M.: Epoxy adhesive formulations. McGrawHill, New York (2006). 